improvements in compliance with guidelines were observed when a structured history sheet was used in neonatal ${ }^{16}$ and antenatal care.$^{17}$ However, the infertility management sheet was used in only a third of couples.

General practitioners were less likely to use the infertility management sheet if the male partner was not registered with the practice. This has implications for the management of infertile couples in primary care. Infertile couples need to be counselled and investigated together. Under the present arrangements it is difficult to provide good quality care if the male partner is registered with another practice. It may be appropriate for a couple registered with different practices to nominate a general practitioner from one practice to coordinate the initial management (and referral, if appropriate) of their infertility.

The use of the infertility management sheet may be improved with a better dissemination strategy including a specific educational initiative which explains the scientific basis of the guidelines and instructs general practitioners in the use of the infertility management sheet. In future, it is likely that clinical guidelines integrated within a computerised medical record will provide similar decision support to the paper based infertility management sheet. ${ }^{18}$

We particularly wish to thank Dr J Farquharson, Dr T Stewart, and Dr S Tuttle, who were involved in the development of the general practice guidelines, and Dr D S Irvine for his help in designing the infertility management sheet. We also wish to thank all general practitioners in Grampian region who participated in the study.

1 Templeton A, Fraser C, Thompson B. The epidemiology of infertility in Aberdeen. $B M{ }^{\gamma} 1990 ; 301: 148-52$.

2 Templeton A, Fraser C, Thompson B. Infertility-epidemiology and referral practice. Hum Reprod 1991;6:1391-4.

3 Aral SO, Cates W. The increasing concern with infertility. Why now? IAMA 1983;250:2327-31.

4 Lilford R, Young G. How general practitioners can help subfertile couples. BMF 1992;305:1376-7.

5 The management of subfertility. Effective Health Care 1992;No 3;1-24.

6 Fertility Committee of Royal College of Obstetricians and Gynaecologists. Infertility guidelines for practice. London: RCOG, 1992.

7 Grimshaw J, Russell IT. Do clinical guidelines influence medical practice? Aberdeen: Health Services Research Unit, University of Aberdeen, 1992. (Occasional Paper 13.)

8 Russell IT, Grimshaw J. The effectiveness of referral guidelines: a review of methods and findings of published evaluations. In: Roland $M$, Coulter $A$, eds. Hospital referrals. Oxford: Oxford University Press, 1992.

9 McQueen DV, Gorst T, Nisbet L, Robertson BJ, Smith RJ, Uitenbroek D. $A$ study of lifestyle and health: a computer assisted telephone interview (CATI) survey. Interim report. Edinburgh: Research Unit in Health and Behavioural Change, 1989.

10 Marinker $M$, Wilkin D, Metcalfe DH. Referral to hospital: can we do better? $B M 7$ 1988;297:461-4.

11 Emmanuel J, Walter N. Referrals from general practice to hospital outpatient departments: a strategy for improvement. $B M \mathcal{F}$ 1989;299:722-4.

12 Helliwell PS, Wright V. Referrals to rheumatology. BMF 1991;302:304.

12 Helliwell PS, Wright V. Referrals to rheumatology. BMJ 1991;302:304.

13 National Audit Office. NHS outpatient services. London: HMSO, 199

14 Haines A, Feder G. Guidance on guidelines. BMF 1992;305:785-6.
15 Guidelines for doctors in the new world. Lancet 1992;339:1197-8.

15 Guidelines for doctors in the new world. Lancet 1992;339:1197-8. medical education using clinical algorithms. A controlled-trial assessment of effect on neonatal care. AfDC 1986;140:791-7.

17 Lilford RJ, Kelly M, Baines A, Cameron S, Cave M, Guthrie K, et al. Effect of using protocols on medical care: a randomised trial of three methods of taking an antenatal history. $B M \mathcal{F}$ 1992;305:1181-4.

18 Purves I, Cowley C, Bainbridge M, Grimshaw J. Using guidelines. $B M 7$ 1992;305:1364.

(Accepted 21 April 1993)

\title{
Explaining variations in prescribing costs across England
}

\author{
Tony Morton-Jones, Mike Pringle
}

\section{Abstract}

Objective-To derive a predictive model for national prescribing behaviour in terms of basic morbidity and demographic factors.

Design-24 demographic, morbidity, and practice factors were entered into a multiple regression analysis to determine the net ingredient cost per patient.

Setting-The 90 family health service authorities in England for 1989.

Results-For net ingredient cost per patient only two demographic factors (numbers of pensioners and the mobility of the registered population measured by list inflation) and two morbidity related factors (standardised mortality ratios and numbers of prepayment certificates issued) significantly contributed to a multiple regression model. This model explained $81 \%$ of the variation in net ingredient cost per registered patient between family health services authorities. The model also enabled a weighting factor of $4.6(95 \%$ confidence interval 3.2 to 6.7$)$ to be derived for the net ingredient cost for elderly patients (compared with the existing prescribing unit factor of 3 ).

Conclusions-The model shows that variations in prescribing costs essentially reflect demand. It also suggests that the current prescribing unit value of 3 for patients aged 65 or more underestimates the extra costs of prescribing for elderly patients.

\section{Introduction}

Prescribing is not uniform across Britain, ${ }^{1-4}$ variations existing between prescribers, practices, health authorities, and regions. For 1990-1, for example, the average annual prescribing costs per patient for the 90 family health services authorities in England ranged

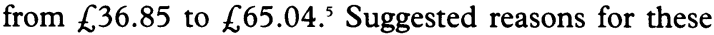
variations include the large differences in socioeconomic factors, patients' attitudes, ${ }^{6}$ and demography across the country, which yield differing levels of health care demand. ${ }^{7}$ Unexplained variations in resource use are, however, liable to be interpreted as indicating inefficiency. It is therefore important for primary care needs assessment to explore the relation between prescribing and socioeconomic and demographic features, both in general and in certain therapeutic groups. '

It is difficult to assess these links at practice level since local factors, such as the general practitioner's own beliefs about prescribing (which have been shown to be stable and unchanging ${ }^{8-10}$ ) and differing levels of identification of morbidity, can be distorting. The coarser the level of analysis the less individual prescribing habits affect the overall picture, but the less sensitive the analysis becomes to real local variation in need. Analysis of data aggregated at the level of the family health services authority is a compromise, but it may disguise real differences between, say, inner city and rural components within one authority. Some work with this approach has been reported. ${ }^{11-13}$ This paper examines a model to explain the variation in prescribing costs at the level of the family health services authority to establish the extent to which such variations are predictable.

\section{Methods}

We identified 24 factors which might influence prescribing costs. The data for each of these factors 
(shown in table I) were obtained for each of the 90 family health services authorities in England from the 1989-90 health services indicator dataset ${ }^{14}$ and the 1991 Regional Trends. ${ }^{15}$

To measure prescribing costs we used the average net ingredient cost per patient for each family health services authority for 1989 . The total cost of a prescription includes the cost of the drug or appliance (the net ingredient cost), a dispensing fee, a container allowance, an on cost allowance, a discount (a negative figure), and, for dispensing doctors, value added tax (VAT). Dispensing doctors bear VAT on items dispensed whereas pharmacies can recover it. If we had used total prescription costs in the analysis areas with a high number of dispensing practices would show an artificially raised value compared to those with few because of the VAT component. Furthermore, the costs due to fees and container allowances are proportional to the number of items prescribed, not the cost of those items, so further complicating the analysis. Hence the net ingredient costs of prescribed items provides a clearer picture of prescribing behaviour without financial complications-a factor ignored in a previous study." Prescriptions are included in the cost of a family health services authority if they are dispensed within its boundary.

In this study two definitions of the denominator population were used. The registered population is based on patients who are registered with a general practitioner in a particular family health services authority area but not necessarily resident in that area. The registered population is used by the Prescription Pricing Authority to calculate net ingredient prescribing cost per patient.

The second definition is the Office of Population Censuses and Surveys population in each family health services authority area. Until data from the 1991 census became available this remained a population projection of the resident population based on the 1981 census data. The figure relates to the resident population within the area covered by the family health services authority, whether or not those people are registered with a general practitioner who is under the administration of that family health services authority. We used this figure to define list inflation-the population registered with the family health services authority as a fraction of the resident population.

TABLE I-Factors entered in multiple regression procedure to determine variations in net ingredient cost per registered patient

\begin{tabular}{|c|c|c|c|}
\hline Factor & Mean & Range & $\begin{array}{c}\text { Correlation } \\
\text { coefficient with } \\
\text { net ingredient } \\
\text { cost per patient }\end{array}$ \\
\hline (1) Net ingredient cost per registered patient $(£)$ & $40 \cdot 32$ & $27 \cdot 23-50 \cdot 71$ & $1 \cdot 00$ \\
\hline (2) No of GPs per 10000 patients & $5 \cdot 1$ & $4 \cdot 6-5 \cdot 8$ & $0 \cdot 11 \mathrm{NS}$ \\
\hline (3) $\%$ Of GPs with lists $<1000^{\star}$ & 1.91 & $0 \cdot 00-11 \cdot 88$ & $-0.22(0.02)$ \\
\hline (4) $\%$ Of GPs with lists $>2500$ & $10 \cdot 76$ & $0 \cdot 00-26 \cdot 70$ & $-0.18(0.04)$ \\
\hline (5) $\%$ Of patients who are dispensing patients & 4.9 & $0 \cdot 0-29 \cdot 1$ & $0.04 \mathrm{NS}$ \\
\hline (6) $\%$ Of dispensing GPs ${ }^{\star}$ & 10.9 & $0 \cdot 0-51 \cdot 8$ & $0.05 \mathrm{NS}$ \\
\hline (7) $\%$ Of single handed GPs ${ }^{\star}$ & $12 \cdot 2$ & $1 \cdot 72-30 \cdot 4$ & -0.05 NS \\
\hline (8) $\%$ Of GPs aged $>65^{\star}$ & 3.41 & $0 \cdot 00-16 \cdot 13$ & $-0.25(0.009)$ \\
\hline (9) Average population density (patients per hectare) & $17 \cdot 8$ & $0 \cdot 6-96 \cdot 5$ & $-0.21(0.02)$ \\
\hline (10) No of pharmacies per 10000 patients & $2 \cdot 18$ & $1 \cdot 4-6 \cdot 5$ & $-0.21(0.03)$ \\
\hline \multirow{2}{*}{\multicolumn{4}{|c|}{ (11) No of exemption certificates issued per 10000 patients in }} \\
\hline & $182 \cdot 4$ & $30 \cdot 8-336 \cdot 7$ & $-0.25(0.009)$ \\
\hline (12) Jarman score ${ }^{\star}$ & $100 \cdot 4$ & $68 \cdot 9-153 \cdot 3$ & $0 \cdot 18(0.05)$ \\
\hline (13) Average No of ancillary staff per GP & 1.46 & $1 \cdot 1-1 \cdot 9$ & $0.10 \mathrm{NS}$ \\
\hline (14) Average No of ancillary staff per practice & $4 \cdot 18$ & $2 \cdot 1-7 \cdot 0$ & $0.06 \mathrm{NS}$ \\
\hline (15) Average No of practice nurses per GP & $0 \cdot 17$ & $0 \cdot 04-0 \cdot 32$ & $-0.24(0.01)$ \\
\hline (16) Average No of practice nurses per practice & 0.51 & $0 \cdot 09-1 \cdot 16$ & $-0 \cdot 16 \mathrm{NS}$ \\
\hline (17) No of FHSA staff per 10000 resident population & $1 \cdot 0$ & $0 \cdot 2-2 \cdot 6$ & $-0.16 \mathrm{NS}$ \\
\hline \multicolumn{4}{|l|}{ (18) No of movements on and off doctors' registers as } \\
\hline percentage of registered population & $30 \cdot 6$ & $14 \cdot 4-51 \cdot 1$ & $-0.25(0.008)$ \\
\hline (19) Average No of GPs per practice & $2 \cdot 81$ & $1 \cdot 67-4 \cdot 15$ & $0.05 \mathrm{NS}$ \\
\hline (20) $\%$ Of population aged $<5$ & 6.65 & $5 \cdot 50-8 \cdot 62$ & $-0 \cdot 10 \mathrm{NS}$ \\
\hline (21) $\%$ Of resident patients who are pensioners & $18 \cdot 32$ & $14 \cdot 50-26 \cdot 10$ & $0.31(0.001)$ \\
\hline (22) List inflation ${ }^{\star}$ & $107 \cdot 1$ & $98 \cdot 1-146 \cdot 1$ & $-0.51(<0.001)$ \\
\hline (23) All causes standardised mortality ratios & $102 \cdot 6$ & $76 \cdot 7-136 \cdot 5$ & $0.44(<0.001)$ \\
\hline \multirow{2}{*}{$\begin{array}{l}\text { (24) \% Of resident population aged } 16-65 \text { unemployed } \\
\text { exempt resident population }\end{array}$} & 5.55 & $1 \cdot 93-12 \cdot 85$ & $0.39(<0.001)$ \\
\hline & $210 \cdot 9$ & $64 \cdot 0-405 \cdot 1$ & $0.64(<0.001)$ \\
\hline
\end{tabular}

*Not normally distributed (Kolmogorov-Smirnov test $<0 \cdot 1$ significance level).
Registered patient lists may be higher than resident populations because of patients who leave a practice area but fail to reregister with a new practice and so remain on the old practice list. List inflation is most severe in inner city areas, where population flux is high (especially inner London). The effect is artificially to reduce the cost per patient in these areas. In the analysis we treated list inflation as an independent variable, even though it is essentially a biasing factor. We did this for two reasons.

Firstly, most prescribing information available uses registered patient populations as denominators. Prescribe and cost information issued by the Prescription Pricing Authority (PACT data) to general practitioners and family health services authorities and data presented in Prescription Pricing Authority annual reports all work with registered populations.

Secondly, list inflation, although an artefact, is a concept that health service workers should be conversant with as it affects practices as well as administrative areas. Direct comparisons of net ingredient costs per registered patient between say an inner city practice and a rural practice may in fact be inappropriate. Use of list inflation as an independent variable in our model should help engender such an appreciation.

Five year all causes standardised mortality ratios for Family Health Services Authority residents between the ages of 0-64 were used. The link between standardised mortality ratios and measures of morbidity has been established, ${ }^{117}$ but we also used the number of prepayment certificates issued (per 10000 registered population not exempt from prescription charges on grounds of age) in the model as a measure of morbidity. People with chronic diseases who are not old or young enough to be exempt from prescription charges are likely to buy prepayment certificates (or season tickets) to limit their prescription costs.

Older people are known to incur higher prescribing costs per head than the rest of the adult population. Around 1983 an attempt was made to accommodate this by giving patients aged 65 and over a weighting factor of three whereas the rest had a weighting of unity. Hence a patient of 65 or over counted as three prescribing units (known as PUs) and those aged less than 65 were counted as one prescribing unit. Prescribing units are used in the reporting of prescribing information to general practitioners and family health services authorities (PACT data). We wanted to assess whether the much disputed ${ }^{1819}$ weighting factor of 3 accurately reflected the amount of extra prescribing for the elderly. In our model the numbers of elderly people were taken as the percentage of the population at or over pension age ( 60 for women, 65 for men).

The 24 factors were examined individually for correlation with net ingredient cost per patient. As some of the factors were not normally distributed, the Spearman rank correlation coefficient was used. Linear least squares multiple regression was used on the SPSS-PC package to predict the prescribing behaviour of each family health services authority in England in terms of net ingredient costs per patient, using the forward selection followed by backward elimination procedure. No forward selected variables were removed on the backward procedure. To test the validity of the final model, we examined the residuals for normality by the Kolmogorov-Smirnov test and for any trend by plotting the residuals versus the predicted value for net ingredient cost per registered patient.

\section{Results and comment}

Most of the 24 factors used as independent variables in the initial multiple regression model showed no separate correlation with net ingredient cost per 
TABLE II-Regression coefficients, significances, and percentage contributions of factors used in net ingredient cost per patient multiple regression model

\begin{tabular}{lccccc}
\hline Regression detail & $\begin{array}{c}\text { List } \\
\text { inflation }\end{array}$ & $\begin{array}{c}\text { Standardised } \\
\text { mortality ratio }\end{array}$ & $\begin{array}{c}\% \\
\text { Pensioners }\end{array}$ & $\begin{array}{c}\% \text { Prepayment } \\
\text { certificates }\end{array}$ & Constant. \\
\hline Regression coefficient & -0.307 & 0.175 & 0.877 & 0.0254 & 33.81 \\
$\mathrm{t}$ & -8.09 & 9.07 & 6.84 & 4.62 & 5.86 \\
Significance & $<0.0001$ & $<0.0001$ & $<0.0001$ & $<0.0001$ & $<0.0001$ \\
\%Variation explained & 44.7 & 65.0 & 75.8 & 80.7 & 0 \\
\hline
\end{tabular}

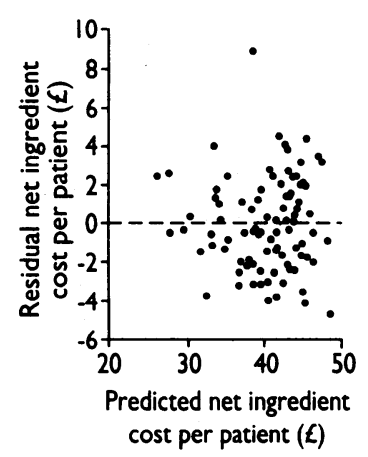

Multiple regression model of national data on family health services authorities: residual (actual-predicted) net ingredient cost per patient versus predicted net ingredient cost per patient using list inflation, percentage of pensioners, standardised mortality ratio, and percentage of prepayment certificates

patient (table I). In fact, not surprisingly, the four factors used in the final model showed the greatest individual correlation. Of the four factors used in the final model, two were demographic factors and two morbidity related factors. The final multiple regression in average net ingredient cost per registered patient. Similar results (in terms of regression coefficients) were obtained when net ingredient cost per resident patient was used as the dependent variable (except that list inflation was not a significant factor). The residuals from the analysis were examined. The KolmogorovSmirnov test showed that the residuals were normally distributed at the 0.4 significance level. The plot of residuals (actual minus predicted values) versus the predicted value showed no discernible trend (see figure). The linear multiple regression model therefore appeared to be appropriate for this analysis. There was, however, one outlier, whose absolute value for the standardised residual was 3.6 (see figure). This was the only value greater than 2 . It was not possible to determine reasons for this family health services authority's strong departure from the national trend, but omission of the data point did not significantly alter the results of the analysis.

From the final model and the regression equation predicting prescribing costs for each family health services authority we were also able to derive a value for aged over 60 (see appendix). The net ingredient cost for each such patient was 4.6 times the cost for patients beneath retirement age. This is higher than the widely used value of 3 , which refers to men and women over 65 . However, the inclusion of women aged between model (table II) explained $81 \%$ of the national variation the prescribing unit for men aged over 65 and women 60-64 in our model should, if anything, have reduced the derived value.

\section{Discussion}

Our results show a high degree of prediction for prescribing variations at family health services authority level. The fact that some $81 \%$ of the national variation has been explained by these demographic factors and morbidity indicators does support the belief that family health services authorities with high prescribing costs are merely responding to demand as opposed to being inefficient.

The forward selection process discounted 20 of the 24 factors entered in the analysis, thus leaving four significant factors. Some of the other factors may indeed be significantly correlated to net ingredient cost per patient, but they will be colinear with one of the four final factors. For example, unemployment rates, despite recent evidence that they are a good predictor of prescribing, comparable to standardised mortality ratios, ${ }^{20}$ do not appear in the final model. From a causal point of view, the factors in the final model may mask other underlying causes of high prescribing. However, the model does not address the issue of causation: it is predictive.

The standardised mortality ratios regression coefficient is positive (see table I), reflecting the expected rise in prescribing with increasing morbidity. However, it is conceptually difficult to see how this factor can deal satisfactorily with those chronic illnesses which do not result in increased mortality. ${ }^{12}$ The appearance of the number of prepayment certificates in the national model supports this belief, as prepayment certificates are issued to patients needing many prescriptions, among them the chronically sick.

An independent derivation of the prescribing unit weighting for elderly people can also be obtained from the model. The value of 4.6 (95\% confidence interval 3.2 to 6.7 ) is $50 \%$ higher than the value used by the Prescription Pricing Authority in its PACT data. The implication is therefore that areas with high numbers of elderly patients may appear to be overprescribing because the value for the prescribing unit is inaccurate.

The derivation of the prescribing unit from our model suggests that the prescribing unit for registered patients in effect varies from area to area. Inner city areas (especially inner London) have high list inflation, but only among the relatively young and mobile. Hence in these areas the prescribing cost per patient for registered patients who are aged less than 65 is artificially lowered relative to that of the elderly registered population who do not move area so frequently, thereby raising the local prescribing unit. In rural areas, where list inflation is less significant, the prescribing unit will be lower. Van Zwanenberg et al recently calculated two differing values for the prescribing unit of 3.6 for a practice in Sunderland and 5.2 for a practice in Telford. ${ }^{18}$ While this could be due to bias from the small numbers of elderly in a single practice, it could also reflect the effects of list inflation at a practice level.

Departures from the model may occur through factors likely to influence prescribing costs which are peculiar to a small number of family health services authorities. For example, authorities with a high proportion of dispensing practices, ${ }^{21}$ and those which contain a large mail order appliance contractor, are both likely to show increased prescribing costs. In the latter example, all items dispensed by such a contractor will appear under the costs of the family health services authority of its location, even though they are often for patients living and registered in other family health services authorities.

We thank Lincolnshire Family Health Services Authority for funding this project; Paul Dixon of the Centre for Health Economics at York for supplying the health services indicator dataset to us, and David Whynes of the Department of Economics, University of Nottingham, for many useful discussions.

\section{Appendix}

The national prescribing unit (PU) is derived from the models as follows:

From the regression coefficients in table II, the predictive equation for the net ingredient cost per registered patient (NPP, in $€$ ) from the multiple regression analysis is:

$$
N P P=0.175 \times S M R+0.0254 \times \% p c-0.307 \times l i+0.877 \times 100 \times f_{p}
$$

-where SMR is the standardised mortality ratio, \%pc is the percentage of patients with prepayment certificates, li is list inflation, and $f_{p}$ is the fraction of patients who are pensioners. Putting the first three terms together, the predicted net ingredient cost per patient can be thought to be composed of two terms, a pensioners term $\left(87 \cdot 7 f_{p}\right)$ and the rest $(r)$. The value $r$ represents the net ingredient cost per patient for the family health services authorities if no patients are pensioners $\left(f_{p}=0\right)$. This corresponds therefore to the average net ingredient cost per patient for the non-pensioners. NB the pensioner term does not correspond to the net ingredient cost per patient for the pensioners; it corresponds to the increase to the overal net ingredient cost per patient the pensioners make. We have therefore for net ingredient cost per patient (NPP):

$$
N P P=r+b f_{p}
$$

However, another approach to calculating the overall average net ingredient cost per registered patient is to take the average of the pensioners' and the non-pensioners' net ingredient cost per patient, weighted by the relative propor- 
tions of the population in each category. The net ingredient cost per patient for the non-pensioners is simply $r$ (from the regression equation). The net ingredient cost per patient for the pensioners will be some factor times $r$. This factor, by definition, is the prescribing unit (PU). Furthermore if the fraction of all patients is $f_{p}$, then the fraction of nonpensioners is $1-f_{p}$. Putting this information together gives an alternative expression for net ingredient cost per patient:

$$
N P P=\left(P U . f_{o}+\left(1-f_{p}\right)\right) r
$$

Simple rearrangement of equation 3 yields the following expression for the prescribing unit, PU:

$$
P U=\frac{\left(\frac{N P P}{r}-\left(1-f_{p}\right)\right)}{f_{p}}
$$

Hence given values for $r, \mathrm{NPP}$, and $f_{p}$, we can derive a value for the prescribing unit. To arrive at the quoted estimate of $4 \cdot 6$, the national average figures for actual net ingredient cost per registered patient $(£ 40.32)$ and the fraction of patients who are pensioners $(0 \cdot 183)$ was used (this allows $\mathrm{r}$ to be estimated from equation 2). These figures are the average value of average net ingredient cost per patient for the 90 family health services authorities, rather than the overall average. Accepting these figures as true values-that is, ignoring any error in the reporting of the data-the error in calculating the prescribing unit stems mainly from the error in estimating $r$ from the regression equation 2. From the analysis, the regression coefficient and its standard error for the pensioners' term is $0.877(0 \cdot 128)$. The standard error of $r$ $\left(=N P P-87.7 \times f_{p}\right)$ is then $0.877 \times 100 \times f_{p}$, giving a value of $2 \cdot 34$. The value for $r$ with a $95 \%$ confidence interval is therefore $r=24 \cdot 27 \pm 4 \cdot 59$. Finally the $95 \%$ confidence interval for PU can be estimated by inserting the upper and lower confidence values for $r$ into equation 4 . This calculation gives $\mathrm{PU}=4.6(95 \%$ confidence interval $3 \cdot 2$ to $6 \cdot 7)$. The upper and lower limits are not symmetrical about the average value because of the inverse (non-linear) relation between the prescribing unit and $r$.
1 Gilleghan JD. Prescribing in general practice. London: Royal College of General Practitioners, 1991. (Occasional paper 54.)

2 Bradley CP. Decision making and prescribing patterns-a literature review. Fam Pract 1991;8:276-87.

3 Harris CM, Heywood PL, Clayden AD. The analysis of prescribing in general practice. London: HMSO, 1990.

4 Taylor RJ. General practitioner prescribing. I R Coll Gen Pract 1977;27:79-

5 Prescription Pricing Authority. Annual Repon 1 April 1990-31 March 1991. Newcastle, PPA, 1991:9-11.

6 Virii A, Britten N. A study of the relationship between patients' attitudes and doctors' prescribing. Family Pract 1991;8:314-9.

7 Marinker M. The doctor's role in prescribing. $f$ R Coll Gen Pract 1973;23: 26-9.

8 Harris CM, Jarman B, Woodman E, White P, Fry JS. Prescribing-a suitable case for treatment. London: RCGP, 1984. (Occasional paper 24.)

9 Harris CM, Fry JS, Jarman B, Woodman E. Prescribing-a case for prolonged treatment. Br f Gen Pract 1986;36:148-50.

10 Taylor RJ, Bond CM. Change in the established prescribing habits of general practitioners: an analysis of initial prescriptions in general practice. $\mathrm{Br} f \mathrm{Gen}$ Pract 1991;41:244-8.

11 Forster DP, Frost CEB. Use of regression analysis to explain the variation in prescribing rates and costs between family practitioner committees. Br f Gen Pract 1991;41:67-71.

12 Baker D, Klein R. Explaining outputs of primary health care: population and practice factors. $B M Y$ 1 1991;303:225-9.

13 Mays N, Chinn S, Kit Mui Ho. Interregional variations in measures of health from the Health and Lifestyle Survey and their relation with indicators of health care need in England. I Epidemiol Community Health 1992;46:38-47.

14 NHS Information Services Directorate. Health services indicator dataset 1989 90. London: Department of Health, 1991

15 Central Statistical Office. Regional Trends 26. London: HMSO, 1991

16 Brennan ME, Clare PH. The relationship between mortality and two indicators of morbidity. I Epidemiol Community Health 1980;34:134-8.

17 Mays N, Chinn S. Relation between all cause standardised mortality ratios and two indices of deprivation at regional and district level in England. 7 Epidemiol Community Health 1989;43:191-9.

18 Edwards C, Metcalfe D, Burr A, Watson K, Steward FCN, Jepson MH, van $Z$ wanenberg TD. Influence of patient age on drug costs: an investigation to validate the prescribing unit. Int $\mathcal{\text { I Pharm Pract 1991;1:73-8. }}$.

19 Harris C, Drug costs and the elderly: getting a fairer deal. Prescriber 1990;16:39-40.

20 Morton-Jones AJ, Pringle MAL. The link between unemployment rates and prescribing. Brf Gen Pract (in press)

21 Morton-Jones AJ, Pringle MAL. Prescribing costs in dispensing practices. $B M f$ 1993;306:1244-6.

(Accepted 21 April 1993)

\section{A MEMORABLE PATIENT}

\section{"I've come for my jabs, Sir"}

I looked up from his notes, surprised at this unusua request. We were always behind with the inoculation at the station and I was pleased that I had a volunteer. As I complied with his request he confided that he expected to go overseas quite soon.

"How long have you been in the service?" I asked.

"Only three weeks," he replied. "But I re-enlisted." Then in a conspiratorial tone, "I'm going to be made up to corporal soon."

His behaviour was out of the ordinary but not abnormal

Three weeks later the commanding officer remarked that one of the cooks was misbehaving and asked me to have a look at him. I will call him Jones. Apparently he was terrorising the other cooks, telling them that he was to be promoted, and when he was he'd have them all on charges. Remembering Jones as the keen young airman who wanted to go abroad, I privately thought that the officer in charge of the cook house should try harder to keep his men under control.

I saw Jones the next morning on sick parade. He was neat and tidy, clean and respectful, but slightly mystified as to why he was there. I too was puzzled. Here was a perfectly rational young man, who by all accounts had been larking about with his friends.

I had now missed the diagnosis twice.

Two months passed without further disturbances. Then one day my sergeant came into my office and said that he had a madman in with him. He was frightened that he was going to be attacked.

I went into the office, and who should be there but Jones. He seemed to have calmed down a bit, but was surly.

"What's going on?" I asked.

"This man is holding up my overseas posting," said Jones.

"Don't talk rubbish," I said firmly. "Now push off, and stop being a nuisance."
I had ignored the third diagnostic clue.

It was only 10 minutes later that the fiasco was repeated. This time his behaviour was so obviously abnormal that I had to take notice and I decided that psychiatric help was urgently needed.

"I'm sending you off for a bit," I said, hoping that he would go quietly.

"Oh Sir," he said, "it's the Easter holiday just coming up, do I have to go now?"

"Sorry," I said, "I think it's important that we get you seen as soon as possible."

"Is it about my promotion?"

I grasped at this convenient straw. "You could say it's about your future."

"Oh that's all right then, I really want my promotion to corporal as soon as possible."

Even this diagnostic clue passed me by.

Making a provisional diagnosis of schizophrenia, I quickly arranged his transfer to the psychiatric unit.

Two months later the unit rang me.

"Do you remember Jones?"

How could I forget him? "Yes, of course."

"We eventually found out he has general paralysis of the insane."

"But he's far too young."

"His initial infection was contracted when he was very young, so the disease proceeds much more quickly than usual,"

Delusions he certainly had, poor fellow, but grandeur? I suppose it depends on your station in life.-A P BLOWER is a retired radiologist in Peterborough

We welcome contributions to fillers: $A$ patient who changed $m y$ practice; $A$ paper that changed my practice; $A$ memorable patient The message I would most like to leave behind, or similar topics. 